\section{How to operate for MRCS candidates and other surgical trainees}

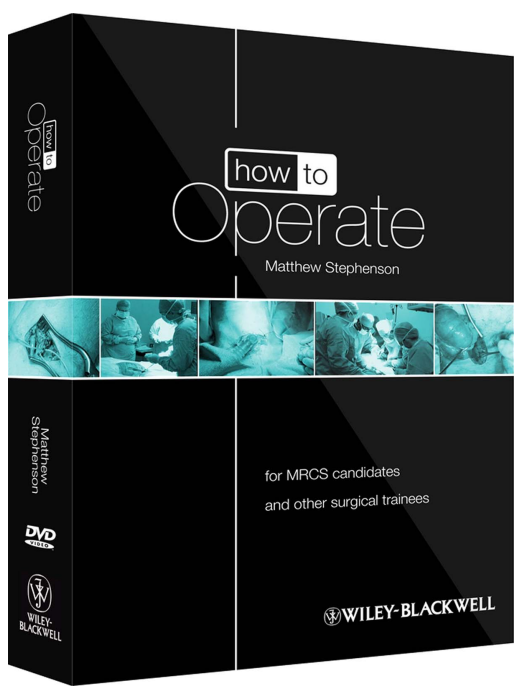

Matthew Stephenson. How to Operate: for MRCS candidates and other surgical trainees. 13 Sept 2011. Price: \$102.37. ISBN: 978-0470657447

How to operate for MRCS candidates and other surgical trainees is an exciting addition to the market for the junior surgical trainee. Uniquely combining a DVD and handbook companion, it provides a step by step guide to more than 40 common operations likely to be encountered during core surgical training. The handbook is aided by intra-operative images highlighting the salient anatomy and surgical points. While notionally aimed as a helpful addition to those studying for the Intercollegiate Membership of the Royal College of Surgeons examination, this compilation has much more scope than that. With the time constraints on training with the European Working Time Directive, the opportunities to have seen, in vivo, a wide range of procedures have become more limited. Therefore, the desire to be fully prepared when attending operating lists has heightened. How to operate provides a solution to this conundrum. Its step by step approach allows the trainee to be, at least, familiar with the techniques surrounding the operation prior to setting foot into the theatre.

The DVD provides a comprehensively narrated guide to operative practice with $10 \mathrm{~h}$ of footage and practical advice to the common pitfalls that may be encountered in the operating theatre. Unlike DVDs aimed at higher surgical trainees, How to operate does not profess to show operations without challenges. Rather, it tackles the realities of the situation that one is likely to encounter.

This compendium is firmly aimed at the core surgical trainee. It covers a breath of surgical procedures likely to be covered during the 2-year rotation: general, vascular, urology, orthopaedics, upper gastrointestinal, breast and colorectal, along with appendices covering basic surgical skills and theatre etiquette. There are inevitably some omissions, for example, the lack of neurosurgical or cardiothoracic procedures. Furthermore, certain specialties fare better than others with orthopaedics and ENT covered somewhat more scantily than the general and urology sections of the DVD and book.

It is surprising that a similar compilation is not already in the market. Those battling with their surgical exams have used Acland's Anatomy for many years, and while its value cannot be negated it is a little dated. Furthermore, How to operate has the added benefit of demonstrating the surgical anatomy as it will be seen in the operating theatre. It will never replace comprehensive operative bibles in the mould of Farquharson's Textbook of Operative General Surgery nor does it purport to. Rather, it provides the junior surgical trainee with a firm grounding. On this note, How to operate will have limited benefit for the higher surgical trainees as they will be familiar with the procedures covered in their parent specialty. However, it opens the possibility of further additions to the series focusing on individual surgical specialties aimed at registrar level trainees.

\section{Neil Shastri-Hurst}

Queen Elizabeth Hospital, Birmingham, UK

Correspondence to Capt Neil Shastri-Hurst, 65 Station Road, Harborne, Birmingham B17 9LP, UK; shastrihurst@doctors.org.uk

\section{Competing interests None}

Provenance and peer review Not commissioned; internally peer reviewed.

To cite Shastri-Hurst N. J R Army Med Corps 2014;160:78.

Published Online First 21 October 2013

J R Army Med Corps 2014;160:78. doi:10.1136/jramc-2013-000176 